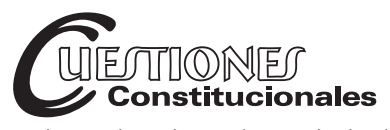

Revista Mexicana de Derecho Constitucional

Núm. 39, julio-diciembre 2018

\title{
El Poder Judicial como protagonista en la definición de las reglas de la competición electoral en Brasil
}

\author{
The Judiciary as the Main Character in Establishing \\ the Rules of Electoral Competition in Brazil
}

\author{
Eneida Desiree Salgado* \\ João Victor ARCHEGAS**
}

RESUMEN: El artículo busca demostrar la fuerza del Poder Judicial, especialmente en la rama electoral, con dos ejemplos: cuando el Tribunal se pronunció sobre el financiamiento de la política y cuando se refirió sobre la división del tiempo de radio y televisión de los partidos políticos, al igual que sobre las reglas de debate electoral. En ambos casos, los ministros del Tribunal evocaron el principio constitucional de igualdad, pero su interpretación desembocó en resultados diferentes: en un caso, conllevó la invalidación de las reglas sobre financiación; en otro, no fue lo suficientemente fuerte para anular la nueva legislación que aniquilaría a los partidos políticos menores. Con la comparación de los fallos es posible sostener que el Poder Judicial es el artífice real de las reglas electorales en Brasil.

Palabras clave: democracia; comicios electorales; igualdad; Poder Judicial; control de constitucionalidad.
ABSTRACT: This paper aims to access such prominence by analyzing two main rulings: when the Court decided about the financing system of political parties and when the Court faced the division of time of electoral propaganda and the rules concerning electoral debates. On both occasions the justices evoked the principle of equality. Nevertheless, the application of such principle triggered two different results. In the first ruling the principle was employed to strike down sections of a federal law on political financing. In the second ruling the same principle wasn't enough to invalidate a new legislation that is known to work against smaller political parties. When this twofold view on equality is duly considered, it becomes feasible to understand how the judicial branch is modifying the rules on electoral competition in Brazil.

Keywords: Democracy; Electoral Arena; Equality; Judicial Branch; Judicial Review.

* Doctora en derecho. Profesora de Derecho constitucional y Derecho electoral en la Universidade Federal do Paraná, Brasil. Investigadora del Núcleo de Investigaciones Constitucionales.desisalg@yahoo.com.br.

** Estudiante de derecho en la Universidade Federal do Paraná. Investigador del CNPq y del Núcleo de Investigaciones Constitucionales.joaovictorarchegas@outlook.com. 
Sumario: I. Brasil y su democracia constitucional. II. La legitimidad del poder político bajo la magistratura y el protagonismo judicial. III. La fuerte exigencia de la igualdad en los comicios electorales, según el Poder Judicial: el caso de la financiación de la política. IV. La casi irrelevancia de la igualdad en los comicios electorales, según el Poder Judicial: el caso de la propaganda electoral. V. Las incoherentes visiones de igualdad en los comicios electorales del Supremo Tribunal Federal y la reforma política bajo la judiciocracia.

VI. Bibliografía.

\section{BRASIL Y SU DEMOCRACIA CONSTITUCIONAL}

La historia de la democracia en Brasil está llena de altibajos. Desde la proclamación de la Independencia — sus dos reinados y los casi 200 años de República-, el país se ha enfrentado frecuentemente a rupturas institucionales, que han afectado sus valores democráticos. La administración pública siempre se ha marcado por una visión patrimonialista y por un rasgo personalista que ha identificado a las prácticas del ejercicio del poder público. ${ }^{1}$

La Constitución de 1988 pretendió revolucionar el anterior escenario estableciendo un Estado democrático de derecho, de matriz fundamentalmente social, basado en premisas republicanas, que no ha conseguido romper la mentalidad individualista y patrimonialista que ha caracterizado a la sociedad brasileña. Asimismo, el nuevo orden constitucional ha buscado garantizar un marco jurídico de seguridad y previsibilidad, al lado de un largo conjunto de derechos sociales y difusos; ampliando la promesa de una democracia electoral, social y económica. La Constitución, en su artículo tercero, tiene como punto de partida y de llegada cuatro objetivos centrales: "construir una sociedad libre, justa y solidaria", "garantizar el desarrollo nacional", "erradicar la pobreza y la marginalización y reducir las desigualdades sociales y regionales", así como "promocionar el bien de

Faoro, Raymundo, "Os donos do poder", Formação do patronato político brasileiro, 3a. ed. rev., São Paulo, Globo, 2001 [1957]; Nunes Leal, Victor, Coronelismo, enxada e voto: o município e o regime representativo no Brasil, 4a. ed., São Paulo, Alfa-Omega, 1978 . 
todos, sin prejuicios de origen, raza, sexo, color, edad y cualesquiera otras formas de discriminación".

La elaboración del texto constitucional se dio bajo un nuevo paradigma constitucional, en su primera fase: el neoconstitucionalismo. Éste representa una ruptura con el juspositivismo, pues reconoce una mayor carga normativa de los principios, al igual que el rol más activo de los jueces en la interpretación y en la resolución del derecho. ${ }^{2}$ Como resume Luis Pietro Sanchís, el neoconstitucionalismo como teoría del derecho supone cinco puntos principales:

más principios que reglas; más ponderación que subsunción; omnipresencia de la Constitución en todas las áreas jurídicas y en todos los conflictos mínimamente relevantes... omnipotencia judicial en lugar de autonomía del legislador ordinario; $y$, por último, coexistencia de una constelación plural de valores, a veces tendencialmente contradictorios... ${ }^{3}$

Una Constitución-proyecto, fruto de una Asamblea Constituyente permeable a la participación popular, ${ }^{4}$ repleta de promesas, impuso muchas tareas al legislador, confiando en los jueces la tarea de concretar sus comandos. Por ello, el sistema jurídico pasó a ser más complejo, combinando los principios con las reglas, en un uso más abstracto e indeterminado del lenguaje jurídico, permitiendo que la lucha política por la definición del texto constitucional se prolongara a la disputa por los significados de los principios de igualdad, libertad, justicia social, función social de la propiedad, etcétera. Así, la magistratura ha sido llamada a constreñir con sus fallos, al resto de poderes públicos, en nombre de la Constitución.

El nuevo régimen político, tras más de 20 años de autoritarismo, fue marcado por nuevas premisas. Es posible reconocer que el Estado brasi-

2 Ochoa Jiménez, María Julia, "Neoconstitucionalismo y cambio de paradigma judicial", Dikaiosyne 15, núm. 27, 2012; Guedes Sobreira, Renan, "Neoconstitucionalismo Latino-americano: as reformas colombianas e os aportes ao direito constitucional brasileiro", en Blanchet, Luiz Alberto et al. (coords.), Eficiência e ética na administração pública, Curitiba, Íthala, 2015, pp. 398-399.

3 Sanchís, Luis Prieto, "Neoconstitucionalismo y ponderación judicial", Anuario de la Facultad de Derecho de la Universidad Autónoma de Madrid, núm. 5, 2001, pp. 201228.

Salgado, Eneida Desiree, Constituição e democracia: tijolo por tijolo em um desenho (quase) lógico: vinte anos de construção do projeto democrática brasileiro, Belo Horizonte, Editora Fórum, 2007. 
leño se ha construido bajo: el principio del Estado de derecho, el principio republicano, el principio democrático, el principio federativo, la soberanía, la ciudadanía, los valores sociales del trabajo e de la libre iniciativa, la dignidad de la persona y el pluralismo político (artículo 1o. constitucional).

El texto constitucional también se preocupa en determinar el contenido y la finalidad de las acciones del poder público. Como se ha mencionado, el artículo 3o. constitucional impone el reconocimiento de un sustrato material de la democracia, con un destino común a la sociedad brasileira. La democracia constitucional es una democracia formal, pero también es una democracia social, económica y cultural. Sin embargo, en una sociedad capitalista fuertemente caracterizada por las diferencias de clase y por una intensa concentración de la renta, las determinaciones constitucionales siguen siendo objeto de una lucha ideológica, con la élite económica que busca impedir las leyes y políticas públicas que permitan superar dicha grieta social.

Para la conformación de la democracia formal, partiendo de los principios republicano y democrático, el sistema jurídico inaugurado con la Constitución de 1988, se funda en cinco principios constitucionales estructurantes: la autenticidad electoral, la libertad para el ejercicio del mandato, la necesaria participación de las minorías en el debate público y en las instituciones políticas, la máxima igualdad en la disputa electoral y la estricta legalidad en materia electoral. ${ }^{5}$ Sin embargo, tales principios no están establecidos con claridad en la Constitución, como pasa con otras ramas, ${ }^{6}$ pero se deducen de distintos principios generales.

Los principios constitucionales electorales deben servir como criterios de fundamentación y aplicación de las reglas de la competencia electoral. Tomando la Constitución como guía para la construcción del sistema jurídico, la legislación electoral debe considerar las bases constitucionales, con reglas compatibles con los principios y sus derivaciones. La reglamentación de las campañas electorales, la propaganda, el financiamiento de la política, la definición del cuerpo electoral y las inelegibilidades, entre

5 Salgado, Eneida Desiree, Principios constitucionais eleitorais, 2a. ed., Belo Horizonte, Editora Fórum, 2015.

6 Como el derecho administrativo, por ejemplo. En este campo, los principios de la legalidad, impersonalidad, moralidad y eficiencia se inscriben en el artículo 37 como los nudos de la trama de la administración pública. 
tantas otras, deben obedecer a los fundamentos constitucionalmente establecidos.

La exigencia de consonancia entre las normas instauradas por el legislador con la Constitución y la delineación constitucional del derecho electoral permite la activación de la jurisdicción constitucional, para controlar las decisiones legislativas, administrativas y judiciales, en materia electoral. Así, la democracia se encuentra con el constitucionalismo en un diseño siempre difícil de plantear y aún más complicado de realizar.

En el campo de las reglas electorales, la controversia entre los dos términos es aún más dramática, pues su objeto es — precisamente- la reglamentación de la competencia electoral, uno de los ejes centrales de la configuración democrática. Por ello, los Estados democráticos deben concentrar su atención en la formulación, la aplicación y la adjudicación de los preceptos electorales, con especial cuidado respecto del control de constitucionalidad y de la interpretación dirigida a garantizar la más amplia e igualitaria competencia electoral.

Desafortunadamente, no es lo que se ve actualmente en Brasil.

\section{LA LEGITIMIDAD DEL PODER POLÍTICO BAJO LA MAGISTRATURA Y EL PROTAGONISMO JUDICIAL}

En el ámbito de los comicios electorales, Brasil realiza elecciones desde el periodo colonial, con una fuerte influencia de la Iglesia Católica en los votantes y en la realización de las elecciones. Hasta el fin de la llamada Primera República — marcado por la "Revolución" de 1930 - el fraude electoral fue constante, principalmente por la violencia. ${ }^{7}$ En contra de lo que llamó "gran fraude", combatiendo la dominación de la voluntad electoral de los ciudadanos por los terratenientes y por los jefes políticos locales, Getúlio Vargas, derrotado en la elección presidencial de 1o. de marzo de 1930, lideró un golpe de Estado que impidió la toma de posesión del presidente electo Júlio Prestes, suspendiendo la vigencia de la Constitución de 1891 y permitiendo el gobierno por decretos. Las banderas de los estados fueron quemadas, simbolizando el fin del federalismo, que hoy se mantie-

7 Nicolau, Jairo, História do voto no Brasil, Río de Janeiro, Jorge Zahar, 2002; Costa Porto, Walter, Dicionário do voto, Brasilia, Universidade de Brasília, 2000; id., A mentirosa urna, São Paulo, Martins Fontes, 2004; id., "História Eleitoral do Brasil", O voto no Brasil: da Colônia à 5 a. República, Brasilia, Senado Federal, vol. 1, 1989. 
ne solamente en el papel. Encabezando el gobierno provisional, Getúlio Vargas reunió las atribuciones del Poder Ejecutivo, del Poder Legislativo $y$, también, del poder constituyente, nombrando una junta de especialistas para determinar las reglas electorales, creando una autoridad electoral. ${ }^{8}$

En 1932, "la verdad electoral" pasó a ser garantizada por un Código Electoral, que entre otras cosas, previó el derecho de voto de las mujeres, el voto secreto, el deber de todo ciudadano de concurrir a la formación, sustentación y defensa de la autoridad pública. La "primera expresión legislativa de la más importante obra que se espera de la Revolución Brasileña de 1930" creó la Justicia Electoral, dejando a cargo de los jueces el reconocimiento de la calidad de elector, la instrucción y decisión de las acciones electorales. ${ }^{9}$ Los juristas de la época veían en la concentración de poder en las manos del Poder Judicial: "la más perfecta garantía de los derechos electorales". ${ }^{10}$

En las elecciones de mayo de 1933, para los integrantes de la Asamblea Constituyente y bajo el control judicial de las elecciones, la participación electoral fue muy baja: solamente $3.3 \%$ de la población compareció a las urnas. Sin embargo, el sistema recibió muchos elogios y alabanzas, pues garantizó "elecciones verdaderas" la autenticidad electoral. ${ }^{12}$

La Constitución de 1934 constitucionalizó la Justicia Electoral, disciplinándola por los órganos del Poder Judicial y reduciendo de manera significativa el rol de las legislaturas nacional y estatales. Irónicamente, la Constitución tuvo una vida brevísima: el mismo líder del golpe (electo indirectamente por la Asamblea Constituyente) decretó estado de emergencia y otorgó una Constitución en 1937. Las elecciones se quedaron suspendidas y el Parlamento se mantuvo cerrado tras el llamado "Estado Nuevo", que perduró hasta 1945. Sin embargo, el "más perfecto sistema

8 Salgado, Eneida Desiree, Administración de las elecciones y jurisdicción electoral: un análisis del modelo mexicano y una crítica a la opción brasilera, México, UNAM, Instituto de Investigaciones Jurídicas, 2016.

9 Según el relator de la 19a. subcomisión legislativa creada por el Decreto núm. 19.459/1930, integrada también por Assis Brasil y Mário Pinto Serva.

10 Rocha Cabral, João C. Da., Código Eleitoral da República dos Estados Unidos do Brasil, Brasilia, Tribunal Superior Eleitoral, 2004, pp. 9, 12 y 18.

11 Costa Porto, Walter, "História Eleitoral...", cit., p. 235

12 Pontes de Miranda, Comentários à Constituição da República dos Estados Unidos do Brasil, Río de Janeiro, Guanabara, 1936, t. I, pp. 728 y 729. 
de control de las elecciones" no pudo garantizar la permanencia del régimen democrático.

Tras la debilitación del Estado Nuevo, una nueva legislación electoral fue presentada: el Decreto-Ley núm. 7.586, de 25 de mayo de 1945, conocido como Ley Agamenon. Con la deposición de Getúlio Vargas por el Alto Comando del Ejército en octubre de 1945, se restableció la Justicia Electoral, organizando elecciones para la Presidencia de la República y para el Parlamento Federal; al igual que de la Asamblea Constituyente. La nueva Constitución subrayó la necesidad de garantizar a los integrantes de la Justicia Electoral el estatuto del Poder Judicial, aunque su nombramiento fue (hasta la fecha) temporal. La Constitución de 1946 judicializó completamente el sistema de control de las elecciones, lo que se confirmó con el Código Electoral de 1950. Casi como un chiste, Getúlio Vargas se eligió presidente de la República en las elecciones de 1950; pero el ex dictador no logró terminar su periodo, suicidándose en 1954.

La inestabilidad política sigue siendo el rasgo de la historia brasileña: los sucesivos gobiernos fueron marcados por reclamos sobre su legitimidad, proporcionando resultados sorprendentes, como la elección de presidente y vicepresidente (Jânio Quadros y João Goulart) de partidos distintos y tendencias ideológicas opuestas, en 1960. Tras siete meses de gobierno y bajo presiones políticas, Jânio renunció en 1961. Las Fuerzas Armadas no querían al vicepresidente progresista para su dirección, ni lo querían en el poder del Parlamento; por ello, una enmienda a la Constitución creó el sistema parlamentario, para permitir la permanencia de Jango (João Goulart) sin poderes y, desde luego, extinguiendo la figura de vicepresidente. La enmienda preveía una consulta popular para cambiar el sistema de gobierno, y en enero de 1963 , el 76.98\% del electorado se manifestó de manera favorable al presidencialismo. Por ende, en 1964 se dio un golpe militar que interrumpió otro hiato democrático en la historia brasileña.

Los actos institucionales del régimen desarmaron la política nacional, acabando con las elecciones directas para la Presidencia de la República, alterando la composición del Supremo Tribunal Federal, garantizando una mayoría complaciente con el nuevo orden, permitiendo la suspensión de derechos políticos y la casación de mandatos del presidente de la República, extinguiendo los partidos políticos (y después instituyendo un bipartidismo). Y para aparentar legitimidad democrática y normalidad institucional, se creó un nuevo Código Electoral en 1965 (que sigue en vigor), 
manteniendo en la Justicia Electoral el control de las elecciones, junto con los fraudes electorales, principalmente de carácter normativo.

Durante los más de 20 años de dictadura, las elecciones transcurrieron bajo la "normalidad" que les permitió el régimen. No hubo reacciones significativas del Poder Judicial ${ }^{13}$ a los cambios legislativos que socavaban la oposición, al igual que tampoco respecto del aplazamiento o cancelación de las elecciones.

El Supremo Tribunal Federal fue condescendiente con el gobierno ilegítimo y en la (nueva) redemocratización actuó fuertemente para mantener su posición en el diseño institucional, junto con los jueces y magistrados. ${ }^{14}$ Todo el Poder Judicial pugnó por una posición fuerte en el nuevo régimen, bajo una Constitución más ambiciosa, empoderándose de manera temeraria.

La Justicia Electoral quedó incólume, como una pieza fundamental del reconocimiento de la validez de la elección de representantes políticos y, por ende, de la legitimidad de la democracia formal. Su lógica, sin embargo, no parece haberse democratizado, quizás por la ausencia de la ruptura en su funcionamiento y su composición, por una baja deferencia a la soberanía popular, o por el apego al Código Electoral de la dictadura militar.

Su posición constitucional es bastante peculiar: es parte del Poder Judicial, como justicia especializada federal, pero no tiene jueces propios, pues actúan como jueces electorales los jueces estatales, por un periodo de dos años, renovable por una vez. Los tribunales regionales electorales (uno por estado y por el Distrito Federal) son compuestos por dos magistrados del Tribunal de Justicia del Estado correspondiente, dos jueces estatales, un magistrado o juez federal y dos abogados (nombrados por la Presidencia de la República); todos ellos por un periodo de dos años, renovable por una vez. El Tribunal Superior Electoral se integra por tres magistrados del

13 De hecho, nos hace falta una investigación más amplia sobre el rol de los juristas en la dictadura, como en Argentina publicó Juan Pablo Bohoslavsky. ¿Usted también, doctor?: complicidad de jueces, fiscales y abogados durante la dictadura, Buenos Aires, Siglo Ventiuno Editores, 2015. Algunos historiadores, sin embargo, ya ensayan algo en este sentido, como Dal Ri Júnior, Arno et al., "O Golpe, o Ato, os Juristas e o STF: Uma história da Recepção da Ditadura no Campo Jurídico", Revista Direitos Humanos e Democracia, núm. 7, enero-junio de 2016.

14 Sobre el tema, vale conferir las investigaciones de Alexandre Douglas Zaidan de Carvalho y, principalmente, los escritos de José Ribas Vieira. Zaidan de Carvalho, Alexandre Douglas, "O Poder Judiciário e a República: a democratização adiada", Revista de Ciência Política, núm. 33, febrero-abril de 1990, pp. 101-107. 
Supremo Tribunal Federal, dos magistrados de Superior Tribunal de Justicia y por dos abogados (nombrados por la Presidencia de la República); quienes permanecen en funciones por un periodo de dos años, renovable por una vez. Lo interesante es que el Supremo Tribunal Federal puede recibir recursos por las decisiones del Tribunal Superior Electoral, pero los magistrados que actúan en la corte electoral participan en el análisis de la apelación, al poder decidirla.

Con dicho diseño institucional, agregado a una práctica de autorreconocimiento de facultades normativas no previstas en la Constitución, la Justicia Electoral es la protagonista en la política brasileña. Son frecuentes las decisiones en contra la soberanía popular, la invalidación de elecciones y la casación de mandatos electivos. Sus eventuales abusos y errores pueden ser corregidos exclusivamente por el Supremo Tribunal Federal, quien muy raramente rechaza las decisiones del Tribunal Superior Electoral, quien, a su vez, tiene entre sus once miembros a tres que también actúan en el órgano de cúspide de la Justicia Electoral (y, por lo tanto, deciden dos veces).

Tras la Constitución de 1988, y principalmente en el nuevo siglo, el Supremo Tribunal Federal se autoproclamó como el lector primigenio de la Constitución, su intérprete máximo y controlador de las demás potestades públicas, pero también como el dirigente del poder constituyente, al banalizar la mutación constitucional (incluso en contra del texto) y al invalidar los cambios constitucionales impulsados por los representantes políticos; por la lectura cuestionable de la Constitución, que es llevada a cabo por jueces y magistrados, principalmente en el ámbito electoral. ${ }^{15}$

El (inconstitucional) liderazgo del Poder Judicial en la definición del sistema normativo es todavía más grave cuando se da en el campo de la democracia formal, en el establecimiento de las reglas de los comicios electorales y del sistema electoral y partidista. Cuando actúa de tal manera, lo hace más allá del rol que la Constitución le atribuye: el sistema de control de las elecciones que, por decisión constituyente, está en las manos de los magistrados; mientras que la construcción del ordenamiento jurídico y la determinación de la regulación electoral le compete al Parlamento.

En los últimos años, varias sentencias judiciales rediseñaron el sistema político brasileño: se inventó judicialmente la necesidad de coherencia en-

15 Lo preocupante es que la lectura innovadora (y usualmente no pro persona) también ocurre en el campo del derecho criminal. 
tre las coaliciones partidistas a nivel federal y a nivel estatal; en cuanto a la fidelidad partidaria, se invalidó la cláusula de desempeño, se rechazó la prohibición de divulgación de encuestas electorales y se anuló el modelo de financiación electoral. Las decisiones que usurpan las facultades del Poder Legislativo no suelen apoyarse en vasta argumentación jurídica y, por veces, no observan las exigencias de coherencia, consistencia y respecto a las decisiones previas.

Se analizarán dos sentencias del Supremo Tribunal Federal para evidenciar el problema en la disputa democrática: una sobre la financiación de la política y otra sobre propaganda y campaña electoral; ambas fundamentadas en el principio de igualdad.

\section{LA FUERTE EXIGENCIA DE LA IGUALDAD EN LOS COMICIOS ELeCtorales, SEgún El Poder Judicial: EL CASO DE LA FINANCIACIÓN DE LA POLÍTICA}

Tras 22 años de vigencia del modelo de financiación, el Supremo Tribunal Federal prohibió los aportes económicos de personas jurídicas para partidos políticos en las campañas electorales el 17 de septiembre de 2015, bajo el argumento de contrariedad a la Constitución. El 24 de febrero de 2016, el dictamen fue oficialmente publicado. La provocación de la jurisdicción constitucional se dio con motivo de la Acción Directa de Inconstitucionalidad núm. 4650, presentada por el Consejo Federal del Orden de los Abogados de Brasil (OAB), con el ministro Luiz Fux como magistrado ponente. ${ }^{16}$

En la acción, el colegio de abogados sostiene la incompatibilidad constitucional de los artículos 23, §1o., incisos I y II; 24; 81, caput y $§ 10$., de la Ley núm. 9.504/97, conocida en Brasil como Ley de las Elecciones, y de los artículos 31; 38, inciso III; 39, caput y §5o., de la Ley num. 9.096/95, la llamada Ley de los Partidos Políticos. Sus argumentos principales se basan en la violación al principio de igualdad, al principio democrático, al principio republicano (todos con rango constitucional), y al principio de la proporcionalidad (en su dimensión de prohibición de protección deficiente), por el modelo mixto de financiación de la política adoptado por Brasil,

16 Brasil, Supremo Tribunal Federal, Acción Directa de Inconstitucionalidad núm. 4650, proponente Conselho Federal da Ordem dos Advogados do Brasil, relator Luiz Fux, Brasilia, 24 de febrero de 2016. 
que debe recibir aportes públicos (oriundos del Fondo Especial de Asistencia Financiera a los Partidos Políticos) con aportes privados (de personas físicas y personas jurídicas).

El Supremo Tribunal Federal reconoció que la Constitución de 1988 no establece un modelo de financiación de la política. Así, para la corte sería necesaria una lectura de los principios constitucionales que rigen el proceso electoral, con la finalidad de determinar un modelo para el legislador, al regular el tema.

La discusión ante los once magistrados de la Corte estuvo centrada en la influencia del poder económico en las elecciones. Una de las preocupaciones nodales era el crecimiento del coste de las campañas, que fue de cerca de 800 millones de reales para la elección presidencial de 2002, a más de 4.5 mil millones de reales en las elecciones municipales de 2012; lo que representó un sustancial incremento. ${ }^{17}$

Desde luego es necesario subrayar que el modelo elegido por el legislador desde 1993 (tras el escándalo de la financiación de la campaña del presidente Collor, que conllevó a su destitución) incluía la posibilidad de aportes de algunas personas jurídicas en las campañas. Las fuentes vedadas eran entidades y gobiernos extranjeros, órganos de la administración directa y fundaciones, concesionarios o permisionarios de servicio público, entidades privadas destinatarias de contribución compulsoria, entidades de utilidad pública, entidades de clase y sindicatos y personas jurídicas sin fines lucrativos que reciban recursos extranjeros (Ley núm. 8.713/1993 y Ley núm. 9.100/1995); entidades benefactoras y religiosas, entidades deportivas, organizaciones no-gubernamentales que recibiesen recursos públicos y organizaciones de la sociedad civil de interés general (Ley núm. 9.504/1997 y sus modificaciones, principalmente a partir de 2006).

De la misma manera, la Ley electoral determina un tope de aportaciones a las campañas electorales: $2 \%$ de la facturación bruta de las empresas del año anterior a la campaña y $10 \%$ del rendimiento bruto para las personas físicas (artículos 81, §1o., y 23, §1o., de la Ley núm. 9.504/1997).

El primer punto cuestionado por la sentencia del Supremo Tribunal Federal se relacionó con la posibilidad de que personas jurídicas influenciaran los comicios electorales, como un ejercicio de ciudadanía. Según el

17 Sarmento, Daniel y Osorio, Aline, Uma mistura tóxica: politica, dinheiro e o financiamento das eleições, p. 07, disponible en: http://www.migalhas.com.br/arqui vos/2014/1/art20140130-01.pdf (acceso el 6 de noviembre de 2016). 
magistrado ponente, la ciudadanía es un ejercicio político propio de las personas naturales y, por lo tanto, no resulta extensible a las personas morales, por lo que tampoco se podría utilizar el argumento de la libertad de expresión, como se hizo en la decisión de la Suprema Corte estadunidense en el fallo Citizens United $v s$. FEC. ${ }^{18}$

En la visión mayoritaria del Tribunal, las personas jurídicas no actuarían de manera compatible con el principio democrático y republicano cuando participan de la financiación de las campañas. En la visión de los magistrados, antes de promocionar el debate político y contribuir al proceso democrático, los aportes empresariales encarecen los comicios y distorsionan la igualdad, permitiendo más oportunidades de éxito al candidato que reúna más dinero en la elección.

Los límites legales también fueron escudriñados, ante la capacidad de financiación proporcional del poder económico. Según la Corte, eso configuraba una medida abusiva e inconstitucional, pues desequilibra la potencialidad de influencia por personas jurídicas en los comicios: una empresa con más intenso poder económico sería capaz de aportar más que otra con menor capacidad financiera.

Contraponiendo más intensamente el argumento de que las aportaciones a campañas electorales representarían el ejercicio de la libertad de expresión de las empresas, el Supremo Tribunal Federal sostuvo que los datos empíricos revelan que las empresas hacen sus aportes sin respetar una lógica de distribución de contribuciones ante las distintas ideologías o programas partidarios. Al revés, para los magistrados, las personas morales invierten en el proceso electoral, inyectando dinero en todos los partidos, incluso adversarios políticos.

También fue ampliamente razonada en el fallo la diferencia establecida por el legislador en cuanto a las distintas personas jurídicas. Para el magistrado ponente, permitir aportaciones de algunas personas jurídicas y prohibir las de otras, representa un agravio al principio de la igualdad. Según su raciocinio, si el fundamento de la regla es impedir la interferencia del poder económico en la arena electoral, la ley debería prohibir que cualquier persona jurídica participe del proceso electoral. Para el magistrado, no habría razón alguna para justificar la posibilidad de aportes económicos

18 Citizens United vs. FEC, 130 S. Ct. 876, 948 núm. 51, 963-4, 2010. 
por parte de las empresas y, al mismo tiempo, vedó las contribuciones por parte de los sindicatos. ${ }^{19}$

La decisión del Supremo Tribunal Federal declaró la inconstitucionalidad parcial del modelo brasileño de financiación de la política, que combina capitales públicos, contribuciones de personas físicas y jurídicas, con la utilización de recursos propios de los candidatos. Según la mayoría de los magistrados, las aportaciones de personas físicas y el uso de capital propio, observando los límites legales, son compatibles con la Constitución, pero no lo son los aportes de las personas jurídicas, al violentar el principio de igualdad.

El artículo 5o. de la Constitución brasileña dispone que "todos son iguales ante la ley, sin distinciones de cualquier naturaleza”. El principio de igualdad atraviesa el texto constitucional, garantizando, entre otros aspectos, la igualdad de oportunidades. Así, los comicios electorales deben darse en condiciones de igualdad de oportunidades.

De la misma manera que el principio de igualdad es un principio fundamental de la República brasileña y de su Estado de derecho, el principio de la máxima igualdad en la disputa electoral es uno de los principios estructurantes del derecho electoral. Se trata de un principio corolario del Estado democrático que mandata a los que disputan un cargo electivo, que lo hagan en condiciones de igualdad. Por ende, se justifican las restricciones normativas al abuso del poder económico, al uso del poder político, a la influencia de los medios de comunicación y a la propaganda electoral, siempre que sean razonables. ${ }^{20}$

Al declarar la inconstitucionalidad de los artículos impugnados, el magistrado Luís Roberto Barroso afirmó que el Supremo Tribunal Federal no estaría considerando como anticonstitucional cualquier aporte de personas jurídicas a las campañas electorales, pero sí el modelo de financiación fija-

19 Dicha comparación parece infundada ante el orden jurídico brasileño. Las entidades sindicales desde luego eran prohibidas de participar de la financiación de partidos políticos y campañas, como todos los entes que reciben, directa o indirectamente, aportes públicos. En el caso específico de los sindicatos, existe previsión legal de contribuciones compulsorias por los trabajadores. Así, sea por su función social, sea por su régimen jurídico, es absolutamente desatinado comparar empresas privadas, que actúan en el mercado sin contribuciones públicas, con los sindicatos o otras organizaciones que funcionan total o parcialmente con dinero público.

20 Salgado, Eneida Desiree, Princípios constitucionais eleitorais, 2a. ed., Belo Horizonte, Fórum, 2015, pp. 189-202. 
do por el legislador, por violentar los principios democrático, republicano e igualdad, al posibilitar la cooptación del interés general por intereses privados.

La sentencia no fue unánime. Por ejemplo, para el magistrado Teori Zavascki, la Constitución brasileña no prevé un modelo de financiación electoral, por lo que no resultarían incompatibles las aportaciones de las personas jurídicas. En su voto, Zavascki subrayó que las distorsiones del sistema de financiamiento no derivan de la ley, sino de condiciones fácicas $\mathrm{y}$, por lo tanto, controlables y fiscalizables; por lo que invalidar el modelo no terminaría con las desigualdades materiales que se suscitan en los comicios electorales. Otro ejemplo de argumento divergente fue el sustentado por el magistrado Gilmar Mendes, quien alertó sobre el peligro del aumento de aportes financieros no registrados en las campañas electorales, al no prever la reducción de los costes de las campañas.

Sin embargo, para la mayoría de los magistrados, el modelo mixto de financiación de campañas electorales, con posibilidad de participación de personas jurídicas viola el principio de igualdad, pues, desde su razonamiento, la cantidad de recursos recaudados por un candidato es un factor decisivo para su elección. Por ello, las corporaciones con distintas capacidades económicas podrían influir de manera desigual en el proceso democrático, ante la ausencia de un tope absoluto de aportaciones. Como resultado, desde tal perspectiva, los comicios electorales se dan en flagrante desigualdad, sea para cargos legislativos, sea para el Poder Ejecutivo.

El posicionamiento de la más alta Corte del Poder Judicial brasileño puede ser resumido en las palabras del magistrado Dias Toffoli, en su contribución al informe de la Organización para la Cooperación y el Desarrollo Económicos sobre la financiación política alrededor del mundo. Según Toffoli, la definición de un tope de aportaciones basado en la facturación bruta contribuye para la desigualdad de oportunidades en los comicios electorales. ${ }^{21}$

Así, sin mencionar una única regla constitucional, asentado en una lectura peculiar del principio de igualdad, el Supremo Tribunal Federal cambió dramáticamente el sistema de financiación de la política, careciendo de legitimidad política al emitir el fallo, sin deferencia del Poder Legislativo.

21 Dias Toffoli, José Antonio, Financing Democracy: Funding of Political Parties and Election Campaigns and the Risk of Policy Capture, París, OECD Publishing, 2016, pp. 183-195. 
Por ello, una alternativa más democrática y constitucional resultaría de considerar que el modelo de financiación con participación de las personas jurídicas, aunque imperfecto, no es inconstitucional, impulsando al legislador para que replantee la participación de la sociedad en la financiación de los partidos y las campañas. ${ }^{22}$

Curiosamente, la misma Corte no consideró tan relevante el principio de igualdad al analizar los cambios en las reglas de propaganda y de debates electorales, en otro fallo. El uso estratégico de los principios constitucionales electorales se hace tangible en la comparación de las dos sentencias: en la primera, la exigencia constitucional de igualdad en el campo electoral fue capaz de invalidar normas jurídicas vigentes hace más de dos décadas; pero, en la segunda, la ausencia de un modelo constitucional de propaganda electoral conllevó a la deferencia con el legislador. Sin embargo, ambas decisiones son equivocadas y débilmente fundamentadas, como se verá posteriormente.

\section{LA CASI IRRELEVANCIA DE LA IGUALDAD EN LOS COMICIOS ELECTORALES, SEgúN EL Poder Judicial: EL CASO \\ DE LA PROPAGANDA ELECTORAL}

Una reforma electoral fue aprobada por el Congreso Nacional brasileño en 2015 y uno de sus principales objetivos se centró en la propaganda electoral. Bajo el argumento de la necesidad de disminuir el coste de las campañas electorales, se redujo el tiempo de exposición de los candidatos $\mathrm{y}$, con él, el de sus ideas, pasando drásticamente de cerca de tres meses a un periodo de alrededor de 45 días, aumentando las restricciones a la propaganda política, pero permitiendo las precampañas. La Ley núm. 13.165/2015 también creó una cláusula de desempeño para la división de

22 Sobre el diálogo interinstitucional como alternativa a la decisión final por las cortes, véase Frazão, Carlos Eduardo, “A PEC do financiamento empresarial de campanhas eleitorais no divã: a constitucionalidade material à luz da teoria dos diálogos institucionais", Revista Brasileira de Direito Eleitoral-RBDE, año 7, núm. 12, enero-junio de 2015, pp. 57-69. Curiosamente, el magistrado ponente sugirió la posibilidad de reconsiderar su decisión en una entrevista concedida en 2017. Sobre eso, véase Salgado, Eneida Desiree y Archegas, João Victor, "Fux e a inconstitucionalidade flutuante: o financiamento de campanhas políticas", 25 de agosto de 2017, disponible en: http://justificando. cartacapital.com.br/2017/08/25/fux-e-inconstitucionalidade-flutuante-questao-do-financiamento-de-campanhas-politicas/ (acceso el 26 de enero de 2018). 
escaños en el sistema proporcional, menoscabando la representatividad de las minorías y alterando la distribución del tiempo de propaganda en radio y televisión. Antes, el tiempo era repartido de la siguiente manera: una tercera parte se distribuía por igual entre los candidatos, mientras que las dos terceras partes restantes le correspondían a la representatividad del partido dominante en la Cámara de Diputados; después de la Ley, solamente 10\% del tiempo es entregado de manera igualitaria.

Los partidos minoritarios también se vieron afectados por el cambio en las reglas de los debates electorales. Antes de la reforma, todos los candidatos de partidos representados en el Congreso Nacional tenían derecho a participar en los debates, siendo permitida la participación de los demás candidatos. Con la reforma, únicamente los candidatos de partidos con representación superior a nueve diputados tendrán la participación garantizada en los debates. Asimismo, las reglas deben ser aprobadas por dos terceras partes de los candidatos de los grandes partidos, lo que lleva a un poder de veto a la participación de candidatos de partidos con menor representación.

La reforma electoral fue ampliamente combatida ante el Supremo Tribunal Federal, por conducto de cinco acciones directas de inconstitucionalidad - ADIs 5423, 5487, 5488, 5491 y 5577-. Uno de los puntos centrales de las impugnaciones consiste en el nuevo reglamento de los debates electorales.

Según la interpretación a la nueva redacción del artículo 46 de la Ley núm. 9.504/1997, dada por la Ley núm. 13.165/2015, las emisoras de radio y televisión están obligadas a invitar exclusivamente a los candidatos presentados por partidos políticos que cuenten con al menos diez diputados. La participación de los demás candidatos depende de la decisión del medio de comunicación y del acuerdo de, mínimamente, dos terceras partes de los candidatos de participación obligatoria. Así, la inclusión de los partidos minoritarios en los debates exige la buena voluntad de los grupos económicos que concentran los medios de comunicación y, por encima de ello, de la anuencia de los grandes partidos.

En las elecciones municipales de 2016, la aplicación de la anterior regla ocasionó la exclusión de los candidatos del Partido Socialismo y Libertad (PSOL) de los debates para presidente municipal. En las dos principales ciudades brasileñas - São Paulo y Rio de Janeiro- la exclusión de Luiza Erundina y Marcelo Freixo de los debates de la TV Bandeirantes 
evidenció la injusticia de la regla. En el momento de su ausencia, Freixo era punteado como segundo lugar en las encuestas en Río de Janeiro, 12\% de intención de votos. ${ }^{23}$ Erundina, por su parte, ostentaba el 9\% de las intenciones de votos en São Paulo, repartiéndose con otros dos candidatos el tercer lugar en los comicios electorales. ${ }^{24}$ Marcelo Freixo, sin embargo, pese a la diferencia de acceso a los medios y a los debates, comparada con el resto de candidatos, fue uno de los más votados en la primera vuelta en Río de Janeiro, aunque fue derrotado en la segunda vuelta por Marcelo Crivella.

Mientras la campaña electoral se desarrollaba, el Supremo Tribunal Federal discutía las acciones directas de inconstitucionalidad y la decisión final fue proferida el 25 de agosto de 2016. Los primeros votos apuntaron a la improcedencia total de las acciones, afirmando su compatibilidad con la Constitución. Sin embargo, el magistrado Roberto Barroso decidió que era procedente, de manera parcial, una de las acciones - la ADI 5488-, cuya autoría fue de la Asociación Brasileña de Emisoras de Radio y Televisión (ABERT), que pretendía establecer el criterio relativo a que si la emisora decidía incluir un candidato que no cumpliera con las exigencias del artículo 46, los demás candidatos no podrían excluirlo.

La decisión final del Supremo Tribunal Federal, capitaneada por el magistrado Barroso, resolvió que solamente podrían participar en los debates de las emisoras, sin ningún criterio razonable, aquellos candidatos pertenecientes a los partidos políticos que contaran con más de nueve diputados. Dicha disposición concentró el poder sobre la igualdad de oportunidades en la más importante modalidad de propaganda electoral — por su alcance y formato, que permite la presentación de programas de gobierno y su contraste con las demás proposiciones- en los pocos dirigentes de las empresas de comunicación en Brasil. Para Daniel Falcão, la tendencia de las reformas electorales y de la lectura del Supremo Tribunal Federal puede llevar a la lenta muerte de los pequeños partidos, cuyos candidatos no tendrán voz ni espacio para difundir sus ideas y proyectos con la sociedad y con los electores. ${ }^{25}$

23 Datos de IBOPE disponibles en: https://www.eleicoes2016.com.br/pesquisa-elei toral-rio-de-janeiro/ (acceso el 8 de noviembre de 2016).

24 Datos de IBOPE disponibles en: https://www.eleicoes2016.com.br/pesquisa-elei toral-sao-paulo/ (acceso el 8 de noviembre de 2016).

25 Pimentel dos Reis, Daniel Gustavo Falcão, O papel do STF na lenta morte dos partidos políticos menores, texto publicado en el sitio JOTA, 30 de agosto de 2016, disponib- 
El criterio fijado por la Corte brasileña en las acciones directas de inconstitucionalidad analizadas no se agota con el tema de los debates electorales. Las acciones también trataban cuestiones relativas al periodo de campaña y al reparto del tiempo de propaganda en radio y televisión, alterado en la reforma electoral promovida por la Ley núm. 13.165/2015, que sigue la tendencia de hacer invisibles las campañas electorales. Dicha propensión antidemocrática fue refrendada por el Supremo Tribunal Federal, pese a su evidente violación al principio de igualdad en los comicios electorales.

De hecho, el legislador brasileño, por sucesivas reformas a la legislación electoral, ha disminuido la campaña electoral. Uno de sus incuestionables ejemplos está en la reglamentación de la propaganda electoral, con reglas crecientemente rígidas, que ha provocado que pocas modalidades de propaganda sean autorizadas, en espacios muy delimitados y por un tiempo diminuto. En los bienes privados, la restricción ha alcanzado la limitación del medio metro cuadrado ${ }^{26}$ - o sea, el ciudadano que desee manifestar su preferencia por determinado candidato o partido está limitado a un pequeño cartel, placa o adhesivo en su morada o coche-.

La esfera pública, el espacio por excelencia del lenguaje político, del debate y la racionalización pública irrestricta — como lo afirman $\mathrm{Kant}^{27}$ y Habermas - ${ }^{28}$ está con el derecho a amordazar. La discusión política desapareció de las calles de las ciudades, con la casi supresión de la libertad de expresión en el periodo electoral. ${ }^{29} \mathrm{El}$ conjunto de impedimentos a la comunicación política, so pretexto de reducir el coste de las campañas, ha limitado el número de competidores en la arena electoral y ha representa-

le en: http://jota.info/e-leitor-o-papel-stf-na-lenta-morte-dos-partidos-politicos-menores (acceso el 6 de noviembre de 2016).

26 TSE, "Eleições 2016: propaganda eleitoral de candidatos deve respeitar restrições da legislação", publicado el 30 de mayo de 2016, disponible en: http://www.tse.jus.br/ imprensa/noticias-tse/2016/Maio/eleicoes-2016-propaganda-eleitoral-de-candidatos-deve-respeitar-restricoes-da-legislacao (acceso el 9 de noviembre de 2016).

27 Kant, Immanuel, Resposta à pergunta: o que é o Esclarecimento?, disponible en http://bioetica.catedraunesco.unb.br/wp-content/uploads/2016/04/Immanuel-Kant.-O-que-é-esclarecimento.pdf (acceso el 19 de noviembre de 2016).

28 Habermas, Jürgen, Fé e saber, trad. de Fernando Costa Mattos, São Paulo, Unesp, 2013.

29 Salgado, Eneida Desiree, "Mais um 7x1, ou o Gore vs Bush da vez", texto publicado en el sitio JOTA, 6 de septiembre de 2016, disponible en: http://jota.info/e-leitor-mais-um-7-x-1-ou-o-gore-vs-bush-da-vez (acceso el 5 de noviembre de 2016). 
do un obstáculo a la creación y al desarrollo de los partidos políticos no hegemónicos. El ordenamiento jurídico, a pesar del pluralismo político, ha configurado uno de los principios fundamentales de la República brasileña que, conforme a la Constitución, impide la actuación efectiva de los partidos menores; al secuestrar la utilización de la comunicación política, al confiscar la conquista del elector y al impedir la posibilidad de crecimiento de la democracia.

La reforma electoral de 2015, además de la drástica reducción del tiempo de campaña, redujo el tiempo de propaganda electoral en la radio y en la televisión. Antes de las elecciones municipales de 2016, la ley electoral reservaba 45 días para la propaganda por los medios y preveía dos horas diarias por bloques y treinta minutos para los spots. Sin embargo, en las elecciones municipales, los candidatos a presidentes municipales que antes contaban con 100 minutos diarios, por 45 días, hasta la reforma de 2015, ahora cuentan con 56 minutos diarios, por 35 días, divididos de manera bastante desigual. Por ello, además de la radical reducción del tiempo de propaganda, la alteración de la fórmula de la distriboución del tiempo violenta de manera directa tanto el principio de igualdad como el de pluralismo político y pluripartidismo.

La reforma fue desafiada en el Supremo Tribunal Federal por los partidos pequeños, que cuestionaron las reglas de los debates y la división del tiempo. Pese a que fueron presentados argumentos que evidenciaban la contravención a los principios constitucionales del pluripartidismo (porque la nueva reglamentación sofoca a los partidos pequeños), del pluralismo político (porque el régimen de la reforma inhibe la exhibición de todas las opiniones políticas al electorado) y de la igualdad (porque la disciplina actual trata de manera absolutamente desigual los partidos políticos); sin embargo, el Supremo Tribunal Federal se pronunció por la constitucionalidad de los cambios, sosteniendo que el constituyente no había establecido un modelo de propaganda electoral. Una alternativa a la decisión hubiera sido aplicar el principio de igualdad, reconociendo el derecho de participación de las minorías en las campañas electorales, conjuntamente con el derecho de oposición, como componente de la democracia. 


\section{LAS INCOHERENTES VISIONES DE IGUALDAD EN LOS COMICIOS ELECTORALES DEL SUPREMO TRIBUNAL FEDERAL Y LA REFORMA POLÍTICA BAJO LA JUDICIOCRACIA}

Las dos decisiones de Supremo Tribunal Federal aquí analizadas versan sobre la reglamentación de los comicios electorales, que son determinantes para la concreción de los principios estructurales de la República, de la democracia y del Estado de derecho. Ambas abordan los modelos legislativos, ante la inexistencia de un modelo constitucional, partiendo del principio de igualdad. Los fallos, empero, son contradictorios, en varios niveles.

En 2015, en el examen sobre financiación privada de la política, la Corte reconoció la inexistencia de un modelo de campaña electoral predefinido por la Constitución, determinando la inconstitucionalidad de los aportes financieros de las personas jurídicas en los procesos electorales —estándar adoptado por la legislación electoral desde 1993-, con fundamento en el principio de la igualdad, aunque lo violente por las razones mencionadas anteriormente. Sin embargo, en 2016, en el análisis de las reglas sobre debates electorales y la partición del tiempo de radio y televisión, la Corte constata la inexistencia de un modelo constitucional de campaña electoral $\mathrm{y}$, por ende, apoya al legislador, a pesar de la afectación al principio de igualdad.

Como se puede observar, el principio de igualdad no operó de la misma manera en ambos casos. En el fallo de la financiación política, su invocación fue suficiente para desplazar la deliberación legislativa, teniendo vigencia hace más de dos décadas, prescindiendo de un argumento jurídico-constitucional que pueda sostener la anulación de lo aprobado por el Poder Legislativo. Los fundamentos del fallo resultan fundamentalmente pragmáticos. En sentido opuesto, la fundamentación de la manutención de la reforma de la comunicación electoral, bajo el principio de igualdad resulta insuficiente descartado por un discurso inusual de acatamiento a la decisión legislativa democrática. Lo más asombroso es que la desigualdad derivada de decisiones de la sociedad y del mercado (que elige a quién financiar en las campañas electorales) es considerada por la Corte como incompatible con la Constitución; sin embargo, la desigualdad derivada del desequilibrio en el acceso a garantías constitucionales como el tiempo de radio y televisión o de la decisión de grupos económicos que dominan 
los medios de comunicación (como en la lectura de las nuevas reglas de los debates) es, para la Corte, conforme a la Constitución.

El Supremo Tribunal Federal no fue coherente en sus decisiones. No consideró su rol en la novela en cadena (como lo exige Dworkin) ${ }^{30}$ ni en la construcción de la catedral (como sostiene Nino). ${ }^{31}$ Los fallos, aunque analizados, con independencia del resto de sentencias de la Corte en materia electoral, no consideran al derecho como integridad, no respetan a la exigencia de integridad, ni interpretan el sistema de derechos como expresión coherente de justicia, ${ }^{32}$ ni comprenden al derecho como una práctica social, en que su decisión compone una labor colectiva sobre cuyo resultado final ningún sujeto o colegiado ejerce control, ${ }^{33}$ tampoco superan los tests propuestos por Gargarella, ${ }^{34}$ al no respetar la consistencia y la igualdad, pues vulneran la práctica democrática y violentan la autonomía.

Además de desmantelar el proyecto constitucional de una democracia ampliamente pluralista, afectando directamente partidos políticos de menor expresión, las decisiones del Supremo Tribunal Federal en el ámbito electoral derivan de criterios subjetivos de justicia e igualdad, desde una lectura perfeccionista, que idealiza a los electores (a veces como ultra capaces, otras veces como infantiles) y que debilita a la democracia. La Corte se empodera en nombre de la protección de la Constitución para construir las reglas de los comicios electorales, sin legitimidad democrática y para preservar el statu quo, ${ }^{35}$ hacia una juristocracia.

Permitir la toma de las decisiones políticas fundamentales y la reforma del sistema político por once magistrados no elegidos democráticamente, que se quedan en su puesto de por vida, significa subvertir a un tiempo la

30 Dworkin, Ronald, $O$ império do Direito, 2a. ed., trad. de Jefferson Luiz Camargo, São Paulo, Martins Fontes, 2007, pp. 275-286.

31 Nino, Carlos Santiago, Fundamentos de derecho constitucional: análisis filosófico, jurídico y politológico de la práctica constitucional, Buenos Aires, Astrea, 2005, pp. 63-66.

32 Dworkin, Ronald, O império do..., cit., p. 441.

33 Nino, Carlos Santiago, La Constitución de la democracia deliberativa, Barcelona, Gedisa, 1996, p. 54.

34 Gargarella, Roberto, El derecho a la protesta, Buenos Aires, Ad-Hoc, 2007, pp. $87-124$.

35 Hirschl, Ran, Towards Juristocracy, Cambridge, First Harvard University Press, 2007. 
democracia y el constitucionalismo, arruinando las promesas de autodeterminación y de representación política.

\section{BiBLIOGRAFÍA}

Bohoslavsky, Juan Pablo, ¿Usted también, doctor?: complicidad de jueces, fiscales y abogados durante la dictadura, Buenos Aires, Siglo Ventiuno Editores, 2015.

Costa Porto, Walter, "História Eleitoral do Brasil", O voto no Brasil: da Colônia à 5 a. República, Brasilia, Senado Federal, 1989, vol. 1.

Costa Porto, Walter, Dicionário do voto, Brasilia, Universidade de Brasilia, 2000.

Costa Porto, Walter Costa, A mentirosa urna, São Paulo, Martins Fontes, 2004.

DAL Ri Júnior, Arno et al., "O Golpe, o Ato, os Juristas e o STF: Uma história da Recepção da Ditadura no Campo Jurídico", Revista Direitos Humanos e Democracia, núm. 7, enero-junio de 2016.

Dias Toffoli, José Antonio, Financing Democracy: Funding of Political Parties and Election Campaigns and the Risk of Policy Capture, París, OECD Publishing, 2016.

Dworkin, Ronald, O império do Direito, 2a. ed., trad. de Jefferson Luiz Camargo, São Paulo, Martins Fontes, 2007.

FAOro, Raymundo, "Os donos do poder", Formação do patronato politico brasileiro, 3a. ed. rev., São Paulo, Globo, 2001.

FrAZÃo, Carlos Eduardo, "A PEC do financiamento empresarial de campanhas eleitorais no divã: a constitucionalidade material à luz da teoria dos diálogos institucionais", Revista Brasileira de Direito Eleitoral, año 7, núm. 12, enero-junio de 2015, pp. 57-69.

Gargarella, Roberto, El derecho a la protesta, Buenos Aires, Ad-Hoc, 2007.

Guedes Sobreira, Renan, "Neoconstitucionalismo Latino-americano: as reformas colombianas e os aportes ao direito constitucional brasileiro", en Blanchet, Luiz Alberto et al. (coords.), Eficiência e ética na administração pública, Curitiba, Íthala, 2015. 
Habermas, Jürgen, Fé e saber, trad. de Fernando Costa Mattos, São Paulo, Unesp, 2013.

Hirschl, Ran, Towards Juristocracy, Cambridge, First Harvard University Press, 2007.

KANT, Immanuel, Resposta à pergunta: o que é o esclarecimento?, disponible en: http://bioetica.catedraunesco.unb.br/wp-content/uploads/ 2016/04/Immanuel-Kant.-O-que-é-esclarecimento.pdf.

Nicolau, Jairo, História do voto no Brasil, Río de Janeiro, Jorge Zahar, 2002.

Nino, Carlos Santiago, Fundamentos de derecho constitucional: análisis filosófico, jurídico y politológico de la práctica constitucional, Buenos Aires, Astrea, 2005.

Nino, Carlos Santiago, La Constitución de la democracia deliberativa, Barcelona, Gedisa, 1996.

Nunes Leal, Victor, Coronelismo, enxada e voto: o municipio e o regime representativo no Brasil, 4a. ed., São Paulo, Alfa-Omega, 1978.

OсноA JimÉnez, María Julia, "Neoconstitucionalismo y cambio de paradigma judicial”, Dikaiosyne 15, núm. 27, 2012.

Pimentel dos Reis, Daniel Gustavo Falcão, "O papel do STF na lenta morte dos partidos políticos menores", texto publicado en el sitio JOTA, 30 de agosto de 2016, disponible en: http://jota.info/e-leitor-o-papel-stf-nalenta-morte-dos-partidos-politicos-menores.

Pontes de Miranda, Comentários à Constituição da República dos Estados Unidos do Brasil, Río de Janeiro, Guanabara, 1936, t. I.

Rocha Cabral, João C. Da., Código Eleitoral da República dos Estados Unidos do Brasil, Brasilia, Tribunal Superior Eleitoral, 2004.

SAlgado, Eneida Desiree, Constituição e democracia: tijolo por tijolo em um desenho (quase) lógico: vinte anos de construção do projeto democrática brasileiro, Belo Horizonte, Fórum, 2007.

Salgado, Eneida Desiree, Princípios constitucionais eleitorais, 2a. ed., Belo Horizonte, Fórum, 2015.

Salgado, Eneida Desiree, Administración de las elecciones y jurisdicción electoral: un análisis del modelo mexicano y una crítica a la opción brasilera, México, UNAM, Instituto de Investigaciones Jurídicas, 2016. 
Salgado, Eneida Desiree, "Mais um 7x1, ou o Gore vs Bush da vez", publicado en el sitio JOTA, 6 de septiembre de 2016, disponible en: http:// jota.infole-leitor-mais-um-7-x-1-ou-o-gore-vs-bush-da-vez.

Salgado, Eneida Desiree y Archegas, João Victor, "Fux e a inconstitucionalidade flutuante: o financiamento de campanhas políticas", publicado el 25 de agosto de 2017, disponible en: http://justificando.cartacapital. com.br/2017/08/25/fux-e-inconstitucionalidade-flutuante-questao-do-financiamento-de-campanhas-politicas/.

SANChís, Luis Prieto, "Neoconstitucionalismo y ponderación judicial", Anuario de la Facultad de Derecho de la Universidad Autónoma de Madrid, núm. 5, 2001.

Sarmento, Daniel y Osorio, Aline, Uma mistura tóxica: politica, dinheiro e o financiamento das eleições, disponible en: http://www.migalhas. com.br/arquivos/2014/1/art20140130-01.pdf.

TSE, "Eleições 2016: propaganda eleitoral de candidatos deve respeitar restrições da legislação", publicado el 30 de mayo de 2016, disponible en: http://www.tse.jus.br/imprensa/noticias-tse/2016/Maio/elei coes-2016-propaganda-eleitoral-de-candidatos-deve-respeitar-res tricoes-da-legislacao.

Zaidan de Carvalho, Alexandre Douglas, "O Poder Judiciário e a República: a democratização adiada", Revista de Ciência Política, núm. 33, febrero-abril de 1990.

Fecha de recepción: 3 de febrero de 2017.

Fecha de dictamen: 30 de octubre de 2017. 